\title{
Correction: Intrafamilial communication of hereditary breast and ovarian cancer genetic information in Italian women: towards a personalised approach
}

Maria Luisa Di Pietro - Drieda Zaçe - Alessia Orfino - Francesca Romana Di Raimo - Andrea Poscia • Elisabetta de Matteis - Daniela Turchetti (D) - Lea Godino (D) - Benedetta Bertonazzi - Marzena Franiuk • Carla Bruzzone - Liliana Varesco (D) Emanuela Lucci-Cordisco • Maurizio Genuardi (D)

Published online: 23 September 2020

(c) The Author(s), under exclusive licence to European Society of Human Genetics 2020

Correction to: European Journal of Human Genetics https://doi.org/10.1038/s41431-020-00723-7

The surname of author Benedetta Bertonazzi was published in the original article as:

\section{Benedetta Beronazzi}

However, this should be:

Benedetta Bertonazzi.

This has been corrected in the original article. 